\title{
IMPACTOS AMBIENTAIS, SOCIAIS E FINANCEIROS DE UMA POLÍTICA DE LOGÍSTICA REVERSA ADOTADA POR UMA FÁBRICA DE TELEVISÃO - UM ESTUDO DE CASO
}

\section{ENVIRONMENTAL, SOCIAL AND FINANCIAL IMPACTS OF A LOGISTICS REVERSE POLICY ADOPTED BY A TELEVISION MANUFACTURER - A CASE STUDY}

\author{
Eduardo Correia Miguez \\ Administrador de Empresas / Mestrando em Engenharia de Produção \\ COPPE/UFRJ \\ Engenharia de Produção \\ Ilha do Fundão - Bloco I Sala 236 CEP 21941-972. \\ Rio de Janeiro - RJ \\ 21 9127-5188 / ecmiguez@yahoo.com.br
}

\author{
Fabrício Molica de Mendonça \\ Administrador de Empresas / Doutorando em Engenharia de Produção \\ COPPE/UFRJ \\ Engenharia de Produção \\ Ilha do Fundão - Bloco I Sala 236 CEP 21941-972. \\ Rio de Janeiro - RJ \\ 21 2562-7848 / fabriciomolica@ yahoo.com.br
}

\section{Rogerio Valle}

Professor do Programa de Engenharia de Produção

COPPE/UFRJ

Engenharia de Produção

Ilha do Fundão - Bloco I Sala 236 CEP 21941-972.

Rio de Janeiro - RJ

21 2562-7848 / valle@ pep.ufrj.br 


\title{
RESUMO
}

A partir da introdução do conceito de sustentabilidade nos modelos de desenvolvimento, a logística reversa tem deixado de ser vista apenas como custos adicionais às organizações, impostos por exigências legais, passando a ser vista como uma vantagem competitiva. $\mathrm{O}$ estudo desenvolvido mostrou - a partir da análise da produção de telas e cones de aparelhos de televisão, com tecnologia CRT - que foi possível aplicar a logística reversa no processo produtivo, obtendo, ao mesmo tempo, resultados ambientais, sociais e financeiros positivos. A obtenção de retornos econômico-financeiros foi medida por meio da aplicação de técnicas do Valor Presente Líquido e Taxa Interna de Retorno.

Palavras-chave: Logística Reversa, benefícios ambientais, benefícios sociais, benefícios financeiros

\begin{abstract}
Since the introduction of the concept of sustainability in development models, the reverse logistics is no longer seen only as additional costs to organizations, demanded by legal requirements but will be seen as a competitive advantage. The study showed from the analysis of the production of screens and cones of television sets with CRT technology, that was possible to apply the reverse logistics in the production process, getting at the same time the environmental, social and financial return. The achievement of economic and financial returns was measured through the application of techniques of Net Present Value and Internal Rate of Return.
\end{abstract}

Key-words: Reverse Logistics, Environmental benefits, Social benefits, Financial benefits

\section{INTRODUÇÃO}

Durante muitos anos, o conceito de desenvolvimento foi interpretado como sinônimo de promoção de crescimento econômico e aumento de riqueza. A partir das conseqüências sociais, ambientais, ecológicas e geográficas desses modelos - que poderiam levar ao colapso 
de toda uma civilização - passa a ser necessária a adoção de um novo modelo que seja capaz de garantir a sustentabilidade dessa sociedade.

Nesse aspecto, o conceito de sustentabilidade é introduzido aos modelos de desenvolvimento de modo que as gerações atuais consigam satisfazer suas necessidades sem comprometer que as gerações futuras também satisfaçam as suas (OUR COMMON FUTURE, 1987). Então, segundo Sachs (1993), a sustentabilidade é alcançada quando é dado o mesmo nível de importância aos aspectos sociais, econômicos, ecológicos, espaciais e culturais. Esses aspectos se inter-relacionam de modo que qualquer alteração em um deles afeta os demais.

A partir da introdução do conceito de sustentabilidade nos modelos de desenvolvimento, surgem com intensidade estudos na área de logística reversa, caracterizada como a área da logística empresarial que busca planejar, operar e controlar o fluxo e as informações logísticas correspondentes, do retorno dos bens de pós-venda e de pós-consumo ao ciclo de negócios ou ao ciclo produtivo, por meio dos canais de distribuição reversos, agregando-lhes valor de diversas naturezas: econômico, ecológico, legal, logístico, de imagem corporativa, entre outros (LEITE, 2003). Esse processo logístico por meio da reciclagem, do reuso, da recuperação e do gerenciamento de resíduos, contribui para diminuir o uso de recursos não renováveis e reduzir ou eliminar resíduos que afetam negativamente o meio ambiente (CARTER \& ELLRAM, 1998).

Com o passar dos anos, a logística reversa tem deixado de ser vista apenas como custos adicionais às organizações, impostos por exigências legais, passando a ser vista como uma vantagem competitiva, pois, por meio dela consegue-se desenvolver melhor relacionamento com os demais agentes da cadeia produtiva, com os clientes e com o mercado (STOCK ET. AL., 2002). Alguns dos trabalhos podem até gerar um ganho econômico adicional para a organização, como é o caso da empresa que é apresentada neste estudo de caso.

O presente trabalho tem por finalidade mostrar os benefícios ambientais, sociais e econômicos, advindos da logística reversa adotada por uma empresa fabricante de televisores que utiliza matéria-prima reciclada, oriunda de telas e cones de computadores, para a fabricação de suas telas e cones. 


\section{LOGÍSTICA REVERSA: DEFINIÇÃO E PRINCIPAIS ATIVIDADES}

Enquanto a logística tradicional trata do fluxo de saída dos produtos, desde o ponto de origem da matéria-prima até o ponto de consumo do produto acabado - de modo a percorrer um caminho de menor custo e que venha atender às necessidades dos clientes - a Logística Reversa tem que se preocupar com o retorno de produtos, materiais e peças ao processo de produção da empresa. Nesse sentido, é conceituada por Rogers \& Tibben-Lembke (1998) como: o processo de planejamento, implantação e controle do fluxo - eficiente e de baixo custo - de materiais, estoques de processo, estoques de produtos acabados e, ainda, informações relacionadas, desde o ponto de consumo até o ponto de origem, com o propósito de recuperar valor ou fazer o descarte de forma apropriada.

Dessa forma, a Logística Reversa passa a significar todas as operações relacionadas com a reutilização de produtos e materiais. Refere-se, assim, a todas as atividades logísticas de coletar, desmontar e processar produtos e/ou materiais e peças usados a fim de assegurar uma recuperação sustentável (DAHER et. al, 2003). Para Prahinski \& Kocabasoglu (2006), no geral, essas atividades englobam:

- O reuso para imediata revenda ou reutilização do produto;

- O upgrade do produto que consiste em reembalar, reparar, reformar ou remanufaturar o produto;

- A recuperação do produto tanto por meio da canibalização - reaproveitamento de alguns componentes dos produtos retornáveis (Kumar e Malegeant, 2005) - quanto por meio da reciclagem;

- O gerenciamento dos resíduos que inclui incineração e envio do resíduo para aterro.

Rogers \& Tibben-Lembke (2001) propõem outra classificação, que é: remanufatura, reforma, reciclagem, descarte em aterro, reempacotamento, processos de retorno, e recuperação.

Apesar de muitas empresas saberem da importância que o fluxo reverso tem, a maioria delas tem dificuldades ou desinteresse em implementar o gerenciamento da Logística Reversa. Existem algumas razões apontadas para a não implementação da Logística Reversa nas empresas. Para Rogers \& Tibben-Lembke (1998), os fabricantes, na maioria das vezes, 
não se sentem responsáveis por seus produtos após o consumo, Há falta de estudos, por parte das empresas, para avaliar os impactos da prática da Logística Reversa na vida das organizações. Nesse sentido, Quinn (2001) afirma que muitos fabricantes acreditam que a Logística Reversa só representa custos. Isso fortalece as práticas de descartes e incinerações com consideráveis danos ao meio ambiente.

Porém, com o desenvolvimento de legislações ambientais mais severas e a conscientização do consumidor sobre a importância do meio ambiente, as empresas estão sendo obrigadas a repensar suas responsabilidades sobre seus produtos após o uso, buscando atuarem na Logística Reversa.

Cabe ressaltar que a própria legislação que regula a forma correta do descarte, tem favorecido estudos no sentido de buscar benefícios econômicos por meio do uso de produtos e resíduos do processo produtivo, uma vez que as empresas passam a ter que decidir entre usar tais produtos ou incorrer em altos custos do correto descarte de lixo (DAHER et. al, 2003).

Rogers \& Tibben-Lembke (1998) aponta também alguns motivos estratégicos para que as empresas atuem na Logística Reversa tais como: diferenciação de serviços; limpeza do canal de distribuição; proteção de margem de lucros; recaptura de valor e recuperação de ativos e; imagem da empresa no mercado.

O crescimento com o verde, ou seja, com o meio ambiente (Fleischmann et al., 2001). Podemos perceber este comportamento, com a crescente valorização de bens produzidos com materiais reciclados.

\section{A UTILIZAÇÃO DA LOGÍSTICA REVERSA NA FABRICAÇÃO DE TELAS E CONES DE TELEVISÃO}

O setor de fabricação de televisores é interessante para se estudar a Logística Reversa, pois permite que seja feita uma análise geral das atividades de uma maneira bem simples. $\mathrm{O}$ 
tubo de raio catódico ou CRT, por exemplo, é um display baseado em uma tecnologia onde uma imagem é criada através de um bombardeamento controlado de elétrons em uma superfície plana coberta com substâncias fosforescentes (Kuehr e Williams, 2003). Esse CRT é formado pela tela, pelo cone, pelo canhão de elétrons e pelas ligas metálicas que prendem os componentes.

O componente principal do CRT (figura 1) é um tubo de vidro com um canhão de elétrons montados na parte final, estreita, e uma ampla área plana, oposta ao canhão, que forma a tela. O canhão dispara elétrons que são, então, refletidos por magnetos para, seletivamente, atingir diferentes partes da tela, que tem camadas fosforescentes que brilham em cores diferentes quando tocados. Uma máscara de buracos logo atrás da tela permite controle apropriado do processo de imagem.

A tela e o cone, usados para a fabricação do CRT possuem substâncias químicas. Essas substâncias entram desde o início do processo de fabricação desses componentes. A tela contém bário e estrôncio e o cone contém chumbo - que é importado do México na forma de granulado, uma vez que o chumbo bruto pode trazer danos às pessoas que o manuseiam no percurso. Todas essas substâncias são prejudiciais à saúde das pessoas que manuseiam esses produtos durante o processo de fabricação e, ainda, quando descartados de forma incorreta, podem trazer danos ao meio ambiente. 


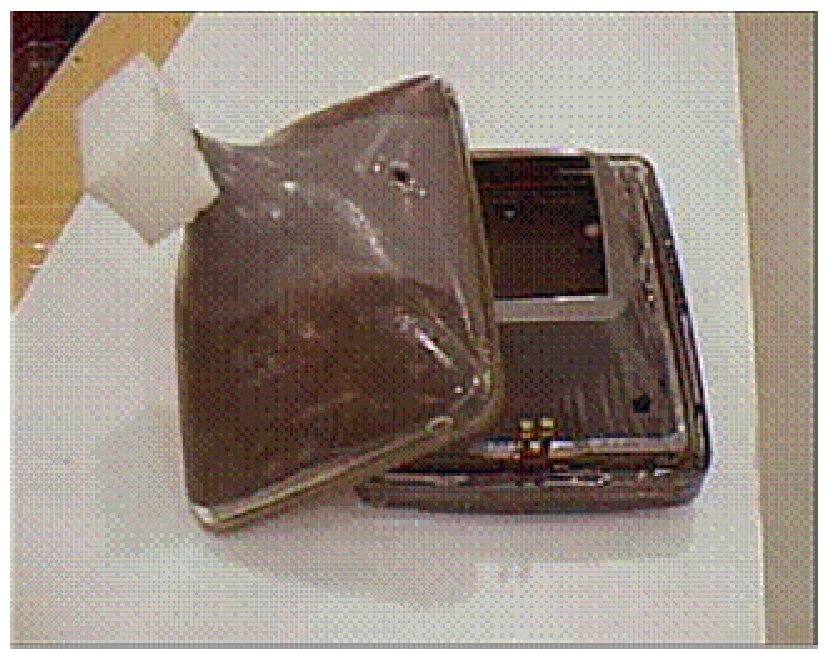

Figura 1 - Ilustração de um CRT

Fonte: Kang e Schoenung, 2005

As telas e cones - componentes usados na fabricação do CRT - são produzidos em uma grande empresa multinacional verticalizada, que internaliza todo o processo produtivo, desde a aquisição de matéria-prima básica para a produção dos componentes até o processo de vendas e comercialização do produto acabado. Para isso, essa empresa possui diversas fábricas para a produção de componentes. As fábricas de telas e cones, por exemplo, localizam-se em cidades diferentes, produzindo, anualmente, em seus fornos, 9,9 milhões de unidades de cada componente ano. Isso representa uma produção diária de 180 toneladas de tela e 130 toneladas de cone.

Durante o processo de produção, ocorre uma perda normal média de $15 \%$ do produto bruto, em ambos os produtos. Geralmente, essa perda ocorre na fase de corte do vidro - ainda na forma pastosa - ou na fase de polimento. Essa perda, se considerada como lixo para descarte, afeta negativamente o meio ambiente, pois, o volume desse lixo, contendo substâncias danosas ao ambiente, seria considerado alto, já que representaria um volume de 46,50 toneladas/dia - considerando 27 toneladas/dia de resíduos provenientes da tela e 19,5 toneladas/dia do cone.

Como forma de reduzir o descarte de vidros contendo chumbo e demais substâncias químicas, prejudiciais ao meio ambiente, a empresa solicitou que fossem feitos testes de 
reaproveitamento desses resíduos, reutilizando-os no processo produtivo. A operação resultou em sucesso, porém, o volume de resíduos diários produzidos era considerado baixo, comparado com a capacidade diária dos fornos e, ainda, com o volume necessário para a composição da matéria-prima - conforme mostra a tabela 1 - que resultaria em benefícios financeiros para a empresa.

Para solucionar esse problema da falta do resíduo, a empresa se empenhou em desenvolver estratégias no sentido de captar o maior volume possível de cacos originados de telas e cones tanto de aparelhos de televisão quanto de monitores de computador.

Cabe ressaltar que as fontes de fornecimento de cacos variam muito, podendo ser grandes organizações, que possuem áreas estruturadas para o envio de partes retornadas; oficinas de conserto de televisões e monitores, que não têm estrutura suficiente para o envio dos equipamentos, sendo, portanto, necessária a ajuda da empresa fabricante para o transporte e; em maior volume, de países estrangeiros - principalmente os Estados Unidos e países da Europa - por meio do processo de importação. Muitas das empresas desses países recebem apoio de seus governos para darem uma destinação adequada para estes produtos, e o envio para um fabricante do material, é considerada uma decisão ambientavelmente aceita. Em 2006 o volume de importação desse material chegou a 40 mil toneladas.

Tabela 1 - Composição da matéria-prima para a produção de telas e cones

\begin{tabular}{|l|c|c|}
\hline \multicolumn{1}{|c|}{ itens } & Telas & Cone \\
\hline Cacos ou resíduos & $75 \%$ & $92,5 \%$ \\
\hline Matéria-Prima virgem & $25 \%$ & $7,5 \%$ \\
\hline Total & $100 \%$ & $100 \%$ \\
\hline Volume diário produção (ton) & 180 & 130 \\
\hline
\end{tabular}

Fonte: Elaboração própria a partir dos dados fornecidos

Todo o material coletado passa por um processo de descontaminação. Depois ocorre o processo de separação entre os elementos orgânicos, metais, não metais, etiquetas, plásticos. O vidro é lavado e depois têm suas propriedades analisadas no laboratório, pois as especificações destes vidros podem ser diferentes das requisitadas para a inserção deles como matéria-prima, ou seja, pode ser necessária a adição ou subtração de substâncias para adequação às exigências para a composição da matéria-prima. Neste processo, geralmente, há $5 \%$ de perda de material. 


\section{BENEFÍCIOS TRAZIDOS PELA UTILIZAÇÃO DE CACOS DE VIDROS PARA A FABRICAÇÃO DE TELAS E CONES}

Os benefícios gerados, decorrentes da utilização de "cacos" na produção de telas e cones de televisores, podem ser divididos em três grupos de benefícios: ambientais, sociais e econômicos.

\subsection{Benefícios Ambientais}

Os benefícios ambientais são traduzidos:

- Na economia de recursos minerais, uma vez que o vidro é composto de diversas substâncias minerais - areia de quartzo, carbonato de potássio, barrilha e feldspato de potássio, entre outros - que, com o reaproveitamento, uma grande quantidade desses recursos é poupada, evitando, também, os impactos decorrentes da extração destes minerais;

- Na diminuição de processos químicos que agridem o meio-ambiente, uma vez que, durante a fabricação do vidro, ocorrem vários processos químicos e manipulações de substâncias perigosas que agridem o meio-ambiente, tais como a barrilha, a sílica, o chumbo, o bário e o estrôncio;

- Na redução de materiais nos aterros sanitários, uma vez que, os tubos, cones e telas de televisão e monitores, por conterem substâncias químicas, não podem ser descartados em qualquer local, pois muitas destas substâncias são perigosas para a saúde;

- Na criação de alternativas de logística reversa para outras empresas, uma vez que, com a utilização de cacos para a composição da matéria-prima, empresas produtoras e/ou usuárias de computadores poderão contar com essa forma de destinação de seus produtos após o uso.

\subsection{Benefícios Sociais}

A manipulação de algumas matérias-primas utilizadas na fabricação dos vidros é prejudicial à saúde daquele que trabalha no transporte, no controle de qualidade e na produção dos bens finais, em virtude da possível ingestão, inalação, contato com a pele e contato com 
os olhos. O contato com essas substâncias pode causar desde alterações nas glândulas de secreção de muco até doenças mais graves como fibrose e câncer. Com a utilização de "cacos" para a produção de telas e cones, a nova forma que essas substâncias se encontram aprisionadas nos cacos - reduz o risco de contaminação pelo trabalhador. Esse pode ser considerado um benefício social da utilização de "cacos" para a composição da matériaprima.

\subsection{Benefícios financeiros}

A utilização de cacos pode trazer dois tipos de benefícios econômicos. O primeiro está relacionado com o aumento da vida útil do forno e o segundo está relacionado com o incremento do retorno de investimento, provocado pela redução do custo de matéria-prima e de energia elétrica.

\subsubsection{Aumento do tempo de vida útil dos fornos}

Ambas as fábricas possuem 1 forno cada. Cada forno mede $100 \mathrm{~m}^{2} \mathrm{e}$ trabalha com uma temperatura média entre $1.200^{\circ} \mathrm{C}$ e $1.600^{\circ} \mathrm{C}$. Para a construção de um forno novo são necessários investimentos no valor de US\$ 8 milhões. Como o tempo de vida útil de cada forno é de 8 anos, consegue-se, por meio de reformas, que custam em média US\$ 5 milhões, prolongar a vida por períodos iguais. Nessas reformas são trocadas todas as partes internas dos fornos e, ainda, parte do refratário.

Com a utilização de "cacos" para a composição da matéria-prima, os fornos podem trabalhar com uma temperatura mais baixa, refletindo nos gastos com energia elétrica e ainda no aumento em 2 anos no tempo de vida útil de cada forno.

Dado o valor do forno, o acréscimo na vida útil é bastante significativo, pois com a utilização de cacos para a composição da matéria-prima, a cada novas reformas, economiza-se o valor de um forno novo.

\subsubsection{Aumento no retorno sobre o investimento}

A utilização de "cacos" na composição de matéria-prima para a fabricação de cacos e cones tem apresentado reduções de custos de $30 \%$, considerando a redução do custo da 
matéria-prima somado com o custo da energia elétrica nos fornos. Essa redução do custo de matéria-prima e energia tem um efeito de redução no custo do componente final tela em $2,71 \%$ e no componente final cone em $3,34 \%$. Este fato ocorre porque os demais custos de produção permanecem os mesmos e, ainda, há aumento de custos relacionados com transporte de cacos, com laboratório de análise e com o processo de limpeza e adequação dos cacos.

Para demonstrar o impacto dessa redução de custos sobre o retorno da empresa, sem expor dados julgados confidenciais, optou-se por confrontar o investimento inicial em fornos com os ganhos provenientes da redução de custos da matéria-prima, por um período de 10 anos, considerando o custo de capital igual a 18,5\% ao ano. Todos os valores foram traduzidos para o Real. Utilizando-se da cotação do dólar igual a R \$ 2, 13 - conforme PTAX de 19/03/2007 - o investimento inicial foi igual a $\mathrm{R} \$ 17.040 .000,00$, o que representa o valor de um forno novo. O custo dos componentes Tela e Cone, com a utilização da matéria-prima virgem e com a utilização de "cacos" para a composição de matéria-prima é mostrado na tabela 2 .

Com a redução do custo dos componentes de cada fábrica, os resultados obtidos antes do Imposto de renda são incrementados em $\mathrm{R} \$ 16.097 .400,00$ para o componente tela e $\mathrm{R} \$$ 16.533.000,00 para o componente cone. Em virtude desse acréscimo de resultados, a empresa aumentará a sua contribuição para o Imposto de Renda em 5.473.116,00 e 5.621.220,00, para os componentes tela e cone, respectivamente. A alíquota desse imposto é de $34 \%$, conforme informações obtidas junto à contabilidade dessas empresas.

Tabela 2 - Custos dos componentes tela e cone em reais

\begin{tabular}{|l|c|c|}
\hline \multicolumn{1}{|c|}{ itens } & Tela & Cone \\
\hline $\begin{array}{l}\text { Custo unitário com a utilização apenas de } \\
\text { Matéria-prima virgem }\end{array}$ & 60,00 & 50,00 \\
\hline $\begin{array}{l}\text { Custo unitário com a utilização da composição } \\
\text { de matéria-prima virgem com cacos }\end{array}$ & 58,37 & 48,33 \\
\hline Redução do custo unitário & 1,63 & 1,67 \\
\hline Volume anual de produção em unidades & 9.900 .000 & 9.900 .000 \\
\hline Redução de custos por ano & $16.097 .400,00$ & $16.533 .000,00$ \\
\hline
\end{tabular}

Fonte: Elaboração própria a partir dos dados fornecidos

A partir desses dados, pôde-se estruturar o fluxo de caixa para a análise. Como as fábricas de tela e cone, localizam em cidades diferentes, cada uma delas possui um forno. Por 
isso, foram estruturados dois fluxos de caixa, conforme mostram as tabelas 3 e 4 . Cabe ressaltar que o ano 0 (zero) é considerado o ano em que foi feito o desembolso inicial em fornos, por isso é representado com o sinal negativo. A partir do ano 1, ocorrem as entradas de caixa, que neste caso são representadas pela redução dos custos dos componentes tela e cone.

Tabela 3 - Levantamento do fluxo de caixa, em reais, para análise do componente tela

\begin{tabular}{|l|l|l|l|l|c|}
\hline \multicolumn{1}{|c|}{ Ano } & $\mathbf{0}$ & $\mathbf{1}$ & $\mathbf{2}$ & $\mathbf{\text { ... }}$ & $\mathbf{1 0}$ \\
\hline Entrada de caixa incremental & $-17.040 .000,00$ & $16.097 .400,00$ & $16.097 .400,00$ & & $16.097 .400,00$ \\
\hline (-) Imposto incremental (34\%) & & $5.473 .116,00$ & $5.473 .116,00$ & $5.473 .116,00$ \\
\hline (=) Fluxo de caixa incremental & $-17.040 .000,00$ & $10.624 .284,00$ & $10.624 .284,00$ & & $10.624 .284,00$ \\
\hline
\end{tabular}

Fonte: Elaboração própria a partir dos dados fornecidos

Tabela 4 - Levantamento do fluxo de caixa, em reais, para análise do componente cone

\begin{tabular}{|l|l|l|l|l|l|}
\hline \multicolumn{1}{|c|}{ Ano } & $\mathbf{0}$ & $\mathbf{1}$ & $\mathbf{2}$ & $\mathbf{\ldots}$ & $\mathbf{1 0}$ \\
\hline Entrada de caixa incremental & $-17.040 .000,00$ & $16.533 .000,00$ & $16.533 .000,00$ & & $16.533 .000,00$ \\
\hline (-) Imposto incremental (34\%) & & $5.621 .220,00$ & $5.621 .220,00$ & & $5.621 .220,00$ \\
\hline (=) Fluxo de caixa incremental & $-17.040 .000,00$ & $10.911 .780,00$ & $10.911 .780,00$ & & $10.911 .780,00$ \\
\hline
\end{tabular}

Fonte: Elaboração própria a partir dos dados fornecidos

A análise dos retornos econômico-financeiros foi feita por meio da aplicação das técnicas Valor Presente Líquido (VPL) e Taxa Interna de Retorno (TIR), adaptadas ao caso específico. Essa adaptação ocorreu uma vez que não foi o propósito desta pesquisa auxiliar decisões em relação à aceitação ou rejeição de projetos e sim de mostrar benefícios econômico- financeiros oriundos da utilização de cacos para a composição de matéria-prima para a produção dos componentes tela e cone.

O Valor Presente Líquido (VPL) é a diferença monetária entre o valor atual de retorno e o investimento inicial, de modo que, todos os fluxos de caixa são medidos em termos monetários atuais. O VPL é obtido pela fórmula 1:

$$
V P L=F C O+\sum_{j=1}^{n} \frac{F C j}{(1+i)^{n}}
$$

Em que:

FC0 - Valor do investimento inicial, lançado com o valor negativo 
FCj - Entradas de caixa

i - custo de capital da empresa

$\mathrm{n}$ - tempo

Neste caso específico, se o VPL>0, significará que apenas a redução provocada pela utilização de cacos para a composição da matéria-prima foi suficiente para cobrir o investimento em um forno e, ainda, sobraram recursos. Isso mostra uma situação muito vantajosa para a empresa.

Já a taxa Interna de Retorno (TIR) é um índice relativo que mede a rentabilidade do investimento por unidade de tempo. É a taxa que torna o valor presente Líquido (VPL) de um fluxo de caixa igual a zero. O cálculo da TIR pode ser dado pela fórmula 2

$$
0=F C O+\sum_{j=1}^{n} \frac{F C j}{(1+i)^{n}}
$$

Neste caso específico a TIR representará a taxa de retorno sobre o investimento inicial, proporcionada apenas pela redução do custo dos componentes tela e cone, em virtude da utilização de cacos para a composição da matéria-prima.

Aplicando-se as fórmulas do VPL e da TIR aos fluxos de caixa dos componentes tela e cone, obteve-se, para a produção de telas, um VPL de R $\$ 29.870 .289,14$ e uma TIR de 62\% e, para a produção de cones, um VPL de R \$ 31.139.694,26 e uma TIR de 64\%. Esses resultados mostram as vantagens que a empresa está obtendo com a redução do custo da matéria-prima na produção dos componentes tela e cone.

\section{CONCIDERAÇÕES}

Este trabalho mostrou - a partir da análise da produção de telas e cones para aparelhos de televisão, com tecnologia CRT - que é possível aplicar a logística reversa no processo produtivo, obtendo benefícios ambientais, sociais e também econômicos para a empresa por meio da utilização de "cacos" na composição da matéria-prima usada na produção de seus componentes.

Os benefícios ambientais podem ser percebidos pela economia na utilização de recursos minerais; pela redução de materiais nos aterros sanitários; pela diminuição de 
processos químicos que agridem o meio ambiente e; pela opção dada, para outras empresas, em relação ao destino de seus produtos e equipamentos após o uso.

Os benefícios sociais foram apontados, com destaque, para os trabalhadores que deixariam de manipular grande parte de substâncias perigosas utilizadas na produção da tela e do cone.

Os benefícios econômicos, para a empresa, podem ser traduzidos no prolongamento da vida útil dos fornos, fazendo com que a empresa reduza investimentos em reformas; no retorno sobre o investimento, obtido por meio da redução de custos dos componentes utilizados para a produção de televisores. Neste trabalho, esses benefícios foram medidos por meio das técnicas do Valor Presente Líquido (VPL) e Taxa Interna de Retorno (TIR) técnicas usadas em análise de investimentos - de modo a mostrar que é possível pensar em uma Logística Reversa que traga retornos financeiros para a empresa.

\section{REFERENCIAS}

BRUNTLAND, G., Our common future: The World Commission on Environment and Development, Oxford, Oxford University Press, 1987.

CARTER, C. R., ELLRAM, L. M. Reverse logistics: A review of the literature and framework for future investigation. International Journal of Business Logistics, 19(1):85-102, 1998.

DAHER, C. E. ; SILVA, E. P. L. S. ; FONSECA, A. P. . Logística Reversa: Oportunidade para Redução de Custos através do Gerenciamento da Cadeia Integrada de Valor. VIII Congreso Internacional de Custos. Anais, Punta del Este, 2003.

FLEISCHMANN, M., BEULLENS, P., BLOEMHOF-RUWAARD, J.M., WASSENHOVE, L.N.V.. The impact of product recovery on logistics network design. Production and Operations Management; vol. 10; n.02, summer, 2001.

KANG, H.Y., SCHOENUNG, J.M. Electronic waste recycling: a review of U.S. infrastructure and technology options. Resources, Conservation \& Recycling 45: 368-400, 2005. 
KUEHR, R., WILLIAMS, E. Computers and the environment - understanding and managing their impacts. Kluwer. Holanda: Academic Publishers. United Nations University, 2003.

KUMAR, S., MALEGEANT, P. Strategic alliance in a closed-loop supply chain, a case of manufacturer and eco-non-profit organization. Technovation 2005.08.002, 2005.

LEITE, P.R.. Logística reversa - meio ambiente e competitividade. São Paulo: Pearson Prentice Hall, 2003.

PRAHINSKI, C., KOCABASOGLU, C. Empirical research opportunities in reverse supply chains. Omega 34: 519-532, 2006.

QUINN, P. Don't get rear-ended by your own supply chain. In:

http://www.idsystems.com/reader/2001/2001_01/comm0101/index.htm Acesso em 06 mai./2007.

ROGERS, D.S., TIBBEN-LEMBKE, RONALD S. Going backwards: reverse logistics practices and trends. Reno, Nevada, Reverse Logistics Executive Council, 1998.

ROGERS, D.S., TIBBEN-LEMBKE, RONALD S.. An examination of Reverse Logistics practices. Journal of Business Logistics. Vol. 22, n.2: 129-148, 2001.

SACHS, I. Estratégia de transição para o século XXI. In: BURZTYN, Marcel (org.) Para pensar o desenvolvimento sustentável. São Paulo: Brasiliense, 1993. 161p.

STOCK, J., SPEH, T., SHEAR, H. Many happy (product) returns. Harvard Business Review, July:16, 2002. 